\title{
Does Personality Provide Indicators of Design Thinking Capacity?
}

\author{
Kuan-Chen Tsai \\ Dept. of Fashion Design, Asia University \\ 500, Lioufeng Rd., Wufeng, Taichung 41354, Taiwan \\ Tel: 886-4-23323456\#108Ｅ-mail: tsaikuanchen@asia.edu.tw
}

Received: Jan. 25, 2019

Accepted: May 17, 2019

Published: May 17, 2019

doi:10.5296/jse.v9i2.14759

URL: https://doi.org/10.5296/jse.v9i2.14759

\begin{abstract}
Design thinking takes an adaptive and holistic view toward product and user needs. It involves engaging in observation, fast learning, visualization, prototyping, and enhancing customer experience. Personality traits have been widely examined in the education field and at the same time design thinking is the main topic of design education. However, until now, there has been a lack of related studies investigating these two variables. As a result, the purpose of the current study is to examine the relationship between design thinking and personalities among Chinese design undergraduates. Convenience sampling was used to recruit 95 first-year Chinese fashion design college students in Taiwan. Two major findings were recorded. Based on zero-order correlations, some variables of personality and of design thinking were positively correlated among our Chinese undergraduates; however, taken as a whole, the structural equation modeling did not support this relationship. Further, age and gender did not play a role in these relationships.
\end{abstract}

Keywords: Design thinking, Personality, Structural equation modeling, Fashion design college students, Taiwan 


\section{Introduction}

Design thinking is a creative problem-solving activity that builds on the principles of design. Design thinking takes an adaptive and holistic view toward product and user needs. It involves engaging in observation, fast learning, visualization, prototyping, and enhancing customer experience (Benson \& Dresdow, 2014; Brown, 2009). Design thinking especially encourages "risk taking, exploration, and creative trade-offs" (Benson \& Dresdow, 2014, p. 455). Benson and Dresdow (2015) argue that design thinking includes four characteristics: analytical thinking (convergent thinking), multiple frames (divergent thinking), reflective thinking (dynamic thinking), and practical reasoning (empathy and visualization). The design thinking process normally consists of five steps: empathize (understand the consumers' needs), define (define and reframe the problem), ideate (brainstorm and generate ideas), prototype (produce mock-ups), and test (experiment; Zarzosa, 2018). In design education, design thinking serves as an important pedagogical tool to help students declare assumptions explicitly and understand the logical links between initial propositions and subsequent thought (Shearer, 2015).

Personality is viewed as a group of various traits and characteristics, includes everything about a person, reflecting a unique and dynamic structure (Eysenk, 1971; Suvarna \& Ganesha Bhata, 2016). Research on personality and its relationships is widely conducted cross many fields (Göncz, 2017; Sharif, 2017). The most widely accepted and studied personality framework is the Five-Factor Model (FFM), which is made up of five dimensions: agreeableness, reflecting likability and friendliness; conscientiousness, which entails dependability and the will to achieve; emotional stability, which includes adjustment and anxiety; extraversion, which relates to activity and sociability; and openness, which includes imaginativeness, broad-mindedness, and artistic sensibility. The value of the FFM is that it includes most of the variance in personality in a simple construct (Digman, 1990). Since personality has significantly impacted on individuals' behaviors, it is worthy to examine the possible influence of personality on people's design thinking ability.

\section{Design Thinking}

The main characteristic of design thinking is a human-centered approach, focusing on meeting the needs of people, through using proper technology and attaining requirements for business achievement (Brown, 2009). Design thinking is the process of creative problem solving, which involves divergent thinking and convergent thinking (IDEO, 2018). Design thinking per se is a cross-disciplinary problem-solving activity. Tim Brown (2008) points out that design thinkers have five salient traits: (1) empathy, (2) integrative thinking, (3) collaboration, (4) experimentalism, and (5) optimism. Design thinking also includes five iterate phases: (1) empathize, to understand your audience and their needs; (2) define, to clarify the issues; (3) ideate, to generate creative ideas; (4) prototype, to demonstrate ideas; and (5) test, to obtain feedback for making better improvements (Tschimmel, 2012). The similarity between design thinking and creative thinking is generating feasible and original ideas. But the biggest difference between design and creative thinking is that design thinking emphasizes empathy, using visual tools, and prototyping. With empathy, designers can deeply understand customers' 
needs and possibly develop useful products that suit the market. Sketching or other valuable visual methods are powerful tools for designers to communicate with other stakeholders in order to collaborate efficiently with other team members. Constructing prototypes could help designers test and obtain useful feedback from users before mass production begins.

The advantages of design thinking include: (a) applying a user-centered approach, (b) stressing empathy, (c) following a fast iterative process, (d) providing a platform for cross-disciplinary experts to deal with complex problems, and (e) generating innovative and practical solutions. Furthermore, learning to use design thinking could help students learn six abilities: (1) learning observation by empathizing with others and knowing the potential problems; (2) obtaining insights while defining the issues and constructing the problems; (3) learning creativity for generating original and unique ideas; (4) showing actualization by bringing ideas into prototyping; (5) learning to be reflective while testing and verifying the proposed ideas; and (6) learning planning and execution while experiencing the full-cycle design phases.

The learning goal of design thinking is to develop design thinkers, who are creatively confident and self-innovating (Brown, 2009). From the learning pedagogy, learners could become active design thinkers, who use learned knowledge and skills in their personal and career lives. Taking it further, people could become proactive designer thinkers who facilitate design thinking in groups and initiate the concept of design thinking for business innovation. More often, learning for design thinking will combine project-, problem-, and process-based learning in order to maximize students' learning experiences and outcomes.

Based on the five design thinking phases, there are several useful activities and practices that educators could use to practice design thinking in the classroom (IDEO, 2012). First, in the empathy phase, in order to understand others' problems and needs, open-ended questions are asked and interviews are conducted to practice observation and interpretation of situations. Next, in the defining phase, by using mind mapping, metaphors, and crafting a point of view, insights are obtained related to framing the problems to be solved. The key is to spotlight the design space, thereby clarifying the opportunity. After obtaining enough clarity about the issues, brainstorming tactics are used to ideate in team settings. In the fourth phase, we construct fast and cheap prototypes (e.g., with paper) and receive useful feedback and suggestions from others. Further, role-playing could be used to understand the actual use of prototyping in all kinds of scenario. Finally, in the testing stage, surveys are used to ask potential users about their response to the prototype for the sake of further analyzing the strengths and weaknesses of the proposed ideas and action plans.

\section{Personality}

It is believed that personality traits affect a person's behavior and they are usually consistent in various situations (Abu Hussain \& Abu Hussain, 2017). In the education field, the relationship between personality and academic performance has been widely investigated (Perera, McIlveen, \& Oliver, 2015). According to a meta-analysis of personality-academic performance relationships, Porpat (2009) found that academic performance was significantly correlated with agreeableness, conscientiousness, and openness to experiences. In addition, Krach et al. (2016) found that openness can predict reading fluency. Evidence of the importance of 
personality in undergraduates' major choices and major satisfaction was also found (Pritchard et al., 2018). Another study illustrated that personality and life satisfaction were interrelated among middle school students in China (Xie et al., 2016).

In the design and business fields, Roberts et al. (2018) suggested that proactive personality and conscientiousness are key factors that should be taken into consideration in the design education. Another study (Setti et al., 2015) showed the influence of a proactive personality on the training motivation of senior workers. Research findings from Toh, Miller, and Kremer (2013) demonstrated a relationship between personality and exposure to product dissection activities. In short, in design literature, personality has been treated as an important factor shaping designers' skills and capabilities, which in turn affect their creative output.

In terms of creativity, Tsai (2014) found that personality among Taiwanese students was positively related to their creativity. Another study (Al-Dababneh \& Al-Zboon, 2017) indicated that Jordanian primary school teachers' creative personalities and beliefs about creativity were aligned with their perceptions of their practices for fostering children's creativity. The positive relationship between teachers' personality traits and their creativity-fostering pedagogy was also confirmed in another Taiwanese study (Cheung \& Mok, 2018). However, one study (Jeong et al., 2017) showed that no significant relationship exists between a creative personality and employee creativity. Using a measure of the Big Five personality dimensions, several studies suggested that openness to experience is the most significant variable related to creativity and innovation (Dahmen-Wassenberg, Kämmerle, Unterrainer, \& Fink, 2016; Patterson \& Zibarras, 2017). One study examined creativity and personality among design major students. In terms of creativity, Chang, Peng, Lin, and Liang (2015) found that openness predicted originality, whereas openness, conscientiousness, and agreeableness predicted usefulness. These results from the literature illustrate the complexities of personality.

\section{Purpose of the Study}

Personality traits have been widely examined in the education field and at the same time design thinking is the main topic of design education. However, until now, there has been a lack of related studies investigating these two variables. As a result, the purpose of the current study is to examine the relationship between design thinking and personalities among Chinese design undergraduates. Two research questions are asked: What is the relationship between design thinking and the personalities of our participants? And do gender and age play a role in this relationship? The current study is the first to examine these two variables from an empirical perspective. In so doing, it is hoped that we will obtain a better understanding of design thinking among design students.

\section{Methods}

\subsection{Participants}

Convenience sampling was used to recruit 95 first-year Chinese fashion design college students in Taiwan. Among them, $11(11.6 \%)$ were male and $84(88.4 \%)$ female. The average age was $20.39(S D=1.05)$. 


\subsection{Measures}

\subsubsection{Design Thinking}

The Tsai Design Thinking Scale (TDTS; Tsai, 2018) was used to investigate the design thinking profiles of the participants. The TDTS has 16 items with responses recorded on a scale ranging from 1 (strongly disagree) to 5 (strongly agree). The TDTS measures four components of design thinking: reasoning and reflection, ideation, collaboration, and execution. Tsai (2018) reported high internal consistency and a robust four-dimensional factor solution of the TDTS through confirmatory factor analysis. In short, the measurement of the TDTS demonstrates good construct validity and reliability.

\subsubsection{Personality}

The Big Five Inventory (BFI) by Benet-Martinez and John (1998) was used to examine the participants' personalities for the traits of extraversion, agreeableness, conscientiousness, neuroticism, and openness. Extraversion refers to activity and energy, sociability, and expressiveness. Agreeableness encompasses traits such as altruism, heartedness, and modesty. Conscientiousness describes the self-control that facilitates task- and goal-directed behavior. Neuroticism indicates anxiety, sadness, and nervous tension. Lastly, openness relates to the breadth and depth of an individual's life experience. Each of the BFI's 44-items employs one or two prototypical trait adjectives that function as the item core, on to which elaborative and contextual information is added. The participants rated each item on a 5-point scale ranging from 1 (strongly disagree) to 5 (strongly agree). Benet-Martinez and John (1998) reported that the alpha reliabilities of the BFI scales range from .75 to .90 , and that the test-retest reliabilities range from .80 to .90 . Benet-Martinez and John also provided evidence of the BFI's acceptable convergent and construct validity.

\section{Results}

\subsection{Correlational Analysis}

Table 1 shows the means, standard deviations, and intercorrelations among the five variables (extraversion, agreeableness, conscientiousness, neuroticism, and openness) of personality and the four variables (reasoning/reflection, ideation, collaboration, and execution) of design thinking. The relationship among the nine variables was investigated using the Pearson product-moment correlation coefficient. Reasoning and reflection were positively and significantly $(p<.01)$ correlated with extraversion $(r=.29)$, conscientiousness $(r=.30)$, neuroticism $(r=.24)$, and openness $(r=.40)$. Ideation was positively and significantly $(p<.01)$ correlated with extraversion $(r=.52)$ and openness $(r=.60)$. Collaboration was positively and significantly $(p<.01)$ correlated with agreeableness $(r=.44)$. Execution was positively and significantly $(p<.01)$ correlated with agreeableness $(r=.39)$ and conscientiousness $(r=.60)$. 
Table 1. Zero-Order correlations, means, and standard deviations for study variables

\begin{tabular}{|c|c|c|c|c|c|c|c|c|c|}
\hline Variable & 1 & 2 & 3 & 4 & 5 & 6 & 7 & 8 & 9 \\
\hline 1.Extraversion & -- & & & & & & & & \\
\hline 2.Agreeableness & .70 & -- & & & & & & & \\
\hline $\begin{array}{l}\text { 3.Conscientiousnes } \\
\mathrm{s}\end{array}$ & .10 & $.25^{*}$ & -- & & & & & & \\
\hline 4.Neuroticism & -.12 & $.22 *$ & .08 & -- & & & & & \\
\hline 5.Openness & $\begin{array}{l}.56^{*} \\
*\end{array}$ & .14 & .06 & .18 & -- & & & & \\
\hline $\begin{array}{l}\text { 6.Reasoning and } \\
\text { Reflection }\end{array}$ & $\begin{array}{l}.29 * \\
*\end{array}$ & .11 & $\begin{array}{l}.30^{*} \\
*\end{array}$ & $.24 * *$ & $.40 * *$ & -- & & & \\
\hline 7.Ideation & $\begin{array}{l}.52 * \\
*\end{array}$ & -.05 & -.08 & -.06 & $.60 * *$ & $.31 * *$ & -- & & \\
\hline 8.Collaboration & .10 & $\begin{array}{l}.44 * \\
*\end{array}$ & .18 & .002 & .07 & $.31 * *$ & .11 & -- & \\
\hline 9.Execution & .08 & $\begin{array}{l}.39 * \\
*\end{array}$ & $\begin{array}{l}.60 * \\
*\end{array}$ & .09 & -.02 & $.30 * *$ & -.07 & $.37 * *$ & -- \\
\hline$M$ & 3.11 & 3.41 & 3.18 & 3.40 & 3.66 & 3.81 & 3.60 & 3.50 & 3.53 \\
\hline$S D$ & .58 & .39 & .46 & .37 & .50 & .56 & .60 & .59 & .77 \\
\hline \multicolumn{10}{|l|}{$\begin{array}{l}* p<.05 \\
* * p<.01\end{array}$} \\
\hline
\end{tabular}

\subsection{Group Differences}

In order to understand the possible differences in design thinking and personality between the genders, we used an independent-sample t-test to compare the mean scores of the nine measures. Table 2 shows that there were no significant differences between males and females. 
Table 2. Gender differences in the study variables

\begin{tabular}{|c|c|c|c|c|c|c|}
\hline \multirow[b]{2}{*}{ Variable } & \multicolumn{2}{|c|}{ Male } & \multicolumn{2}{|c|}{ Female } & \multirow[b]{2}{*}{$t(93)$} & \multirow[b]{2}{*}{$p$} \\
\hline & $M$ & $S D$ & $M$ & $S D$ & & \\
\hline Extraversion & 3.05 & .58 & 3.12 & .58 & -.42 & .809 \\
\hline Agreeableness & 3.26 & .35 & 3.43 & .39 & -1.36 & .576 \\
\hline Conscientiousness & 3.06 & .48 & 3.19 & .46 & -.90 & .937 \\
\hline Neuroticism & 3.17 & .36 & 3.43 & .36 & -2.24 & .632 \\
\hline Openness & 3.58 & .65 & 3.67 & .49 & -.52 & .088 \\
\hline Reasoning/reflection & 3.73 & .56 & 3.82 & .56 & -.49 & .502 \\
\hline Ideation & 3.82 & .62 & 3.57 & .60 & 1.30 & .787 \\
\hline Collaboration & 3.57 & .56 & 3.49 & .59 & .42 & .741 \\
\hline Execution & 3.27 & .88 & 3.56 & .76 & -1.16 & .631 \\
\hline
\end{tabular}

A two-way between-groups multivariate analysis of variance (MANOVA) was performed to investigate gender and age differences in the nine dependent variables, and gender and age were treated as independent variables. In terms of gender, Table 3 shows that there was a statistically significant difference between males and females in the combined dependent variables, $F(9,78)=2.81, p=.007$, Wilks's Lambda $=.76$, partial eta squared $=.245$. In terms of age, there was no statistically significant difference in the combined dependent variables, $F$ $(9,78)=1.19, p=.175$, Wilks's Lambda $=.47$, partial eta squared $=.119$. With regard to the interaction between gender and age, there was a statistically significant difference in the combined dependent variables, $F(9,78)=2.08, p=.041$, Wilks's Lambda $=.81$, partial eta squared $=.194$.

Because we were conducting a whole series of analyses, we ran the risk of an inflated Type-1 error. In order to minimize the chance of a Type-1 error across multiple tests, we implemented a Bonferroni adjustment by dividing .05 by 9 (which equals .006 after rounding) as our cut-off. When the results for the dependent variables were considered separately (ANOVA), there was no difference in gender and age that reached statistical significance when using a Bonferroni adjusted alpha level of .006 . 
Table 3. Multivariate and univariate analyses of variance for the study variables

\begin{tabular}{|l|l|l|l|l|l|l|l|l|l|l|}
\hline & \multicolumn{7}{|c|}{ ANOVA $F(1,87)$} \\
\hline Variable & $\begin{array}{l}\text { MANOVA } \\
F(9,78)\end{array}$ & P1 & P2 & P3 & P4 & P5 & D1 & D2 & D3 & D4 \\
\hline $\begin{array}{l}\text { Gender } \\
\text { (G) }\end{array}$ & 2.81 & .96 & .001 & 1.20 & 2.53 & .78 & .07 & 4.75 & 5.36 & 4.19 \\
\hline Age (A) & 1.19 & 1.47 & .90 & .44 & 1.54 & 1.55 & 1.76 & 1.00 & .76 & 1.02 \\
\hline G x A & 2.08 & 1.21 & .55 & 3.31 & .02 & .04 & .32 & 2.56 & 5.37 & 7.50 \\
\hline
\end{tabular}

Note. Multivariate $F$ rations are the Wilks's Lambda statistic. $\mathrm{P} 1=$ Extraversion; $\mathrm{P} 2=$ Agreeableness; P3 = Conscientiousness; P4 = Neuroticism; P5 = Openness; D1 = Reasoning/reflection; D2 = Ideation; D3 = Collaboration; D4 = Execution.

\subsection{Structural Equation Modeling}

In our study, structural equation modeling with a generalized least squares estimation was performed using IBM AMOS to test the model structure further. We used the indicators recommended by Hair et al. (2010) to assess goodness of model fit: the goodness-of-fit index. In this index: (GFI; greater than .90 is typically considered good), the comparative fit index (CFI; above .90 usually indicates a good fit), the incremental fit index (IFI; above 90 usually indicates a good fit), and root mean square error of approximation (RMSEA; lower than .08 indicates an acceptable fit). The results demonstrate that the model yielded an unacceptable model fit: $\mathrm{X} 2=68.15, d f=26, p<.001, \mathrm{GFI}=.839, \mathrm{CFI}=.399, \mathrm{IFI}=.474, \mathrm{RMSEA}=.131$.

\section{Discussion}

This study was conducted to examine the relationship between design thinking and personality among Chinese design undergraduates in Taiwan. On the basis of zero-order correlation, we found that the strength of the correlations among the five personality and four design thinking variables was medium. More specifically, reasoning and reflection were correlated with extraversion, conscientiousness, neuroticism, and openness. It is possible that designers with the extraversion and openness traits will have a better chance of identifying problems; with conscientiousness, they can better analyze the problems and think through the situations; and with neuroticism, they are more sensitive to people's needs, helping them to create better design solutions. In addition, we found that ideation was correlated with extraversion and openness, and this finding is supported by other studies (Agnoli, Corazza, \& Runco, 2016; Chang, Peng, Lin, \& Liang, 2015; Chiang, Hsu, \& Shih, 2017). According to the personality literature, extraversion and openness are highly related to creativity. People who have high energy and are open-minded are more creative and have more of a chance to generate unique ideas.

In our study, collaboration was only correlated with agreeableness. In a team setting, designers 
need to work with other experts from different fields, which is quite common in the current business environment. Thus, designers with high agreeableness can easily communicate with others and fit into the working group. Furthermore, execution was correlated with agreeableness and conscientiousness. In order to execute design projects, designers need to work with others and, again, agreeableness will become an important trait that designers should have. Apart from that, conscientiousness is also another important trait that helps designers stay on track when finalizing the desired product on time to enter the market.

When we compared the gender differences in personality and design thinking, the results showed that there was no significant difference. Moreover, when we considered age and the possible interaction between gender and age, again we found no significant difference. In other words, in our sample, age and gender did not have an impact on personality and design thinking.

In order to validate our findings further on the relationship between personality and design thinking, we conducted structural equation modeling. The proposed model did not fit our data well. Taken as a whole, this finding suggests that personality and design thinking are not related. Although, based on zero-order correlations, we found that some components of personality were correlated with those of design thinking, as we treated personality and design thinking as latent variables under the framework of structural equation modeling; this model was not validated. This is the first empirical study to investigate the relationship between personality and design thinking, and clearly more studies are needed to further investigate this relationship.

\section{Limitations}

In drawing our findings, some salient limitations should be noted. First, the cross-sectional design of the current study may have limited the explanation of our findings as we could not validate the causal relations between personality and design thinking. Further studies may utilize longitudinal or experimental designs to measure and compare these undergraduate variables. Second, our homogeneous sample might have influenced the results. Further research could employ a more diverse sample and include different ethnic groups to generate and validate our findings. A third limitation is the use of self-reported measures rather than expert evaluations of behavioral measures. Further studies could use real-life measures of individuals' design thinking performance to validate our findings.

\section{Implications and Conclusion}

Although the limitations of this study must be kept in mind, the results of the current study provide useful insights into the relationship between personality and design thinking. Our research findings are significant for design education professionals. Educators should not only consider how to cultivate design thinking in the classroom, but also recognize that individuals' personalities might affect their design thinking.

In our study, we found no empirical evidence of a strong correlation between design thinking and personality through the structural equation modeling technique. For future researchers, this suggests that more research is needed, since the current study is the first empirical study to 
examine the possible relation between design thinking and personality.

The main objective of this study was to examine the relationship between the personality and design thinking of design undergraduates in Taiwan. Two major findings were recorded. Based on zero-order correlations, some variables of personality and of design thinking were positively correlated among our Chinese undergraduates; however, taken as a whole, the structural equation modeling did not support this relationship. Further, age and gender did not play a role in these relationships. Although there were some salient limitations in the current study, it remains of importance and retains its value. Future research in this line of study seems promising and deserves more attention. Additionally, front-line design teachers should be encouraged to promote the design thinking of their students and at the same time should consider their students' personalities.

\section{References}

Abu Hussain, J., \& Abu Hussain, N. (2017). Personality traits of minority Arab teachers in the Arab educational system in Israel. International Journal of Higher Education, 6(3), 29-39. https://doi.org/10.5430/ijhe.v6n3p29

Agnoli, S., Corazza, G. E., \& Runco, M. A. (2016). Estimating creativity with a multiple-measurement approach within scientific and artistic domains. Creativity Research Journal, 28(2), 171-176. https://doi.org/10.1080/10400419.2016.1162475

Al-Dababneh, K. A., \& Al-Zboon, E. K. (2017). Can teachers' self-reported characteristics and beliefs about creativity predict their perception of their creativity practices in the classroom? International Journal of Special Education, 32(4), 723-745.

Benet-Martinez, V., \& John, O. P. (1998). Los Cinco Grandes across cultures and ethnic groups: Multitrait multimethod analyses of the big five in Spanish and English. Journal of Personality and Social Psychology, 75(3), 729-750. https://doi.org/10.1037/0022-3514.75.3.729

Benson, J., \& Dresdow, S. (2014). Design thinking: A fresh approach for transformtive assessment practice. Journal of Management Education, 38(3), 436-461. https://doi.org/10.1177/1052562913507571

Benson, J., \& Dresdow, S. (2015). Design for thinking: Engagement in an innovation project. Decision Sciences Journal of Innovative Education, 13(3), 377-410. https://doi.org/10.1111/dsji.12069

Brown, T. (2008). Design thinking. Harvard Business Review, 86(6), 84-92.

Brown, T (2009). Change by design: How design thinking transforms organizations and inspires innovation. New York, NY: HarperBusiness.

Chang, C.-C., Peng, L.-P., Lin, J.-S., \& Liang, C. (2015). Predicting the creativity of design majors based on the interaction of diverse personality traits. Innovations in Education and Teaching International, 52(4), 371-382. https://doi.org/10.1080/14703297.2014.999697

Cheung, R. H. P., \& Mok, M. M. C. (2018). Early childhood teachers' perception of creative 
personality as a predictor of their support of pedagogy important for fostering creativity: A Chinese perspective. Creativity Research Journal, 30(3), 276-286. https://doi.org/10.1080/10400419.2018.1488345

Chiang, Y.-H., Hsu, C.-C., \& Shih, H.-A. (2017). Extroversion personality, domain knowledge, and the creativity of new product development engineers.Creativity Research Journal, 29(4), 387-396. https://doi.org/10.1080/10400419.2017.1376501

Dahmen-Wassenberg, P., Kämmerle, M., Unterrainer, H.-F., \& Fink, A. (2016). The relation between different facets of creativity and the dark side of personality. Creativity Research Journal, 28(1), 60-66. https://doi.org/10.1080/10400419.2016.1125267

Digman, J. M. (1990). Personality structure: Emergence of the Five-Factor Model. Annual Review of Psychology, 41, 417-440. https://doi.org/10.1146/annurev.ps.41.020190.002221

Eysenck, H. j., \& Eysenck, S. B. G. (1975). Manual of the Eysenck Personality Questionnaire. London: Hodder and Stoughton. https://doi.org/10.1037/t05462-000

Göncz, L. (2017). Teacher personality: A review of psychological research and guidelines for a more comprehensive theory in educational psychology. Open Review of Educational Research, 4, 75-95. https://doi.org/10.1080/23265507.2017.1339572

IDEO (2012). Design thinking for educators. Retrieved from https://designthinkingforeducators.com/about-toolkit/

IDEO (2018). Design thinking. Retrieved from https://www.ideou.com/pages/design-thinking Jeong, S., McLean, G. N., McLean, L. D., Yoo, S., \& Bartlett, K. (2017). The moderating role of non-controlling supervision and organizational learning culture on employee creativity: The influences of domain expertise and creative personality. European Journal of Training and Development, 41(7), 647-666. https://doi.org/10.1108/EJTD-03-2017-0025

Krach, S. K., McCreery, M. P,. Loe, S. A., \& Jones, W. P. (2016). Do dispositional characteristics influence reading? Examining the impact of personality on reading fluency. Reading Psychology, 37(3), 470-486. https://doi.org/10.1080/02702711.2015.1066908

Patterson, F., \& Zibarras, L. D. (2017). Selecting for creativity and innovation potential: Implications for practice in healthcare education. Advances in Health Sciences Education, 22(2), 417-428. https://doi.org/10.1007/s10459-016-9731-4

Perera, H. N., McIlveen, P., \& Oliver, M. E. (2015). The mediating roles of coping and adjustment in the relationship between personality and academic achievement. British Journal of Educational Psychology, 85(3), 440-457. https://doi.org/10.1111/bjep.12084

Porpat, A. E. (2009). A meta-analysis of the five-factor model of personality and academic performance. Psychological Bulletin, 135(2), 322-338. https://doi.org/10.1037/a0014996

Pritchard, A., Fudge, J., Crawford, E. C., \& Jackson, J. (2018). Undergraduate choice of major and major satisfaction: An expanded role for personality measures. Journal of Marketing for Higher Education, 28(2), 155-174. https://doi.org/10.1080/08841241.2018.1442381 


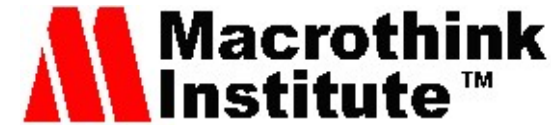

Journal of Studies in Education

ISSN 2162-6952

2019, Vol. 9, No. 2

Roberts, Z., Rogers, A., Thomas, C. L., Spitzmueller, C. (2018). Effects of proactive personality and conscientiousness on training motivation. International Journal of Training and Development, 22(2), 126-143. https://doi.org/10.1111/ijtd.12122

Setti, I., Dordoni, P., Piccoli, B., Bellotto, M., \& Argentero, P. (2015). Proactive personality and training motivation among older workers: A mediational model of goal orientation. European Journal of Training and Development, 39(8), 681-699. https://doi.org/10.1108/EJTD-03-2015-0018

Sharif, R. (2017). A model of creativity in organizations: John Holland's theory of vocational choice (1973) at multiple levels of analysis. Journal of Creative Behavior, 51(2), 140-152. https://doi.org/10.1002/jocb.91

Shearer, A. W. (2015). Abduction to argument: A framework of design thinking. Landscape Journal, 34(2), 127-138. https://doi.org/10.3368/lj.34.2.127

Suvarna, V. D.; Ganesha Bhata, H. S. (2016). A study on academic Achievement and personality of secondary school students. Research in Pedagogy, 6(1), 99-108. https://doi.org/10.17810/2015.27

Toh, C., Miller, S., \& Kremer, G. E. O. (2013). The role of personality and team-based product dissection on fixation effects. Advances in Engineering Education, 3(4), 1-23.

Tsai, K. C. (2014). Taiwanese elementary students' creativity, creative personality, and learning styles: An exploratory study. Alberta Journal of Educational Research, 60(3), 464-473.

Tsai, K. C. (2018). Development of the Tsai Design Thinking Scale. Arts and Design Studies, 69, 44-54.

Tschimmel, K. (2012). Design thinking as an effective toolkit for innovation. In: ISPIM Conference Proceedings of the International Society for Professional Innovation Management (ISPIM). https://doi.org/10.13140/2.1.2570.3361

Xie, Q., Fan, W., Wong, P., \& Cheung, F. M. (2016). Personality and parenting style as predictors of life satisfaction among Chinese secondary students. Asia-Pacific Education Researcher, 25(3), 423-432. https://doi.org/10.1007/s40299-015-0271-0

Zarzosa, J. (2018). Adopting a design-thinking multidisciplinary learning approach: Integrating mobile applications into a marketing research course. Marketing Education Review, 28(2), 120-125. https://doi.org/10.1080/10528008.2018.1452035

\section{Copyright Disclaimer}

Copyright for this article is retained by the author(s), with first publication rights granted to the journal.

This is an open-access article distributed under the terms and conditions of the Creative Commons Attribution license (http://creativecommons.org/licenses/by/3.0/). 